\title{
Effect of Thermoelastic Behavior on Interfacial Debonding and Particulate Fracture in AA1100/TiN Nanoparticulate Metal Matrix Composites
}

\author{
Chennakesava R Alavala \\ Professor, Department of Mechanical Engineering, JNTUH College of Engineering, Kukatpally, Hyderabad - 500 085, Telangana, India

\begin{abstract}
The present work was to assess the effect of thermoelastic behavior on interface debonding and nanoparticulate fracture in AA1100/titanium nitride nanoparticulate metal matrix composites. TiN is used for making of artificial limbs, biological materials and cutting tools. The RVE models were used to analyze thermo-elastic behavior. The stiffness of AA1100/titanium nitride nanoparticle metal matrix composites decreased with the increase of temperature. The debonding of interface/interphase between AA1100 alloy matrix and TiN nanoparticle was observed at temperatures ranging from $0^{\circ} \mathrm{C}$ to $200^{\circ} \mathrm{C}$. Fracture of TiN nanoparticulates was witnessed above $200^{\circ} \mathrm{C}$ heating of the composites.
\end{abstract}

Keywords: AA1100 alloy, titanium nitride, RVE model, thermoelastic, debonding, particulate fracture, finite element analysis.

\section{Introduction}

For metal matrix composites comprising of nanoparticulates and metal matrix, thermal stability is very vital to judge the fitness of these materials in various applications [1, 2]. For matrix materials, aluminum alloys are appreciated because of their low density and high ductility. However, they are deficient in strength and stiffness. Several reinforcing materials were tested to improve strength and stiffness. Important nanoparticulates are silicon carbide [3-6], alumina [7-9], alumina trihydrate [10], carbon $[11,12]$, silicon nitride $[13,15]$, boron carbide [16], titanium boride [17-18], etc.

Titanium nitride ( $\mathrm{TiN}$ ) has high hardness, high-temperature chemical stability and excellent thermal conductivity. TiN is used for making of artificial limbs, biological materials and cutting tools. AA1100 alloy is having excellent forming characteristics. It is broadly employed for manufacturing of fin stock, heat exchanger fins and cooking utensils. The importance of the present work was to combine the forming characteristics of AA1100 alloy and chemical stability and thermal conductivity of TiN nanoparticles.

The present work was to explore the effect of thermoelastic behavior on interfacial debonding and particulate fracture in the nanoparticulate TiN/AA1100 alloy matrix composites. Finite element analysis (FEA) was executed to assess thermoelastic behavior of metal matrix composites using representative volume element (RVE) subjected to hydrostatic and isothermal loading.

\section{Material and Methods}

The shear lag model [19] has been used to describe the build up and transfer of particle stress, $\sigma_{\mathrm{p}}$ from the point where the particle enters the matrix to some point along the particle axis where the tensile stress has decayed to zero. Failure of the particle/matrix interface occurs when the interfacial shear strength, $\tau \max$, is reached.
The shear lag distribution of strain, along a fully bonded particle can be described by [19]

$$
\mathrm{e}_{\mathrm{app}}=\mathrm{e}_{\mathrm{p}} \frac{\operatorname{sibh}\left[\mathrm { n } \left(\mathrm{L}_{\mathrm{e}-\mathrm{x} / \mathrm{r})]}\right.\right.}{\sin \mathrm{H}(\mathrm{ns})}
$$

where $e_{a p p}$ is the strain acting on the particle outside the matrix, $e_{p}$ is the particle strain at a distance $\mathrm{x}$ inside the matrix, Le is the embedded length, $r$ is the particle radius and $s$ is the particle aspect ratio $\left(\mathrm{L}_{\mathrm{e}} / \mathrm{r}\right)$. The $\mathrm{n}$ parameter used in this paper is based on the parameter $[14,15]$ :

$$
\mathrm{n}^{2}=\frac{2}{\mathrm{E}_{\mathrm{p}} \mathrm{E}_{\mathrm{m}}}\left[\frac{\mathrm{E}_{\mathrm{p}} \mathrm{V}_{\mathrm{p}}+\mathrm{E}_{\mathrm{m}} \mathrm{V}_{\mathrm{m}}}{\mathrm{V}_{\mathrm{m}} /\left(4 \mathrm{G}_{\mathrm{p}}\right)+1 /\left(2 \mathrm{G}_{\mathrm{m}}\right)\left(\left(1 / \mathrm{V}_{\mathrm{m}}\right) \ln \left(1 / \mathrm{V}_{\mathrm{p}}\right)-1-\left(\mathrm{V}_{\mathrm{m}} / 2\right)\right)}\right]
$$

where $E_{p}$ and $G_{P}$ ate the particle elastic and shear moduli, $E_{m}$ and $G_{m}$ are the elastic and shear moduli of the matrix. $V_{p}$ is the particle volume fraction and $\mathrm{V}_{\mathrm{m}}$ is the volume fraction of matrix. The corresponding interfacial stress, $\tau$ at a distance $\mathrm{x}$ along the interface, is given by

$$
\tau=\frac{n}{2} E_{p} e_{\text {app }} \frac{\cosh \left[n\left(L_{e}-x\right) / r\right]}{\sinh [n s]}
$$

is a maximum at the crack plane $(\mathrm{x}=0)$. Since both the interfacial shear stress and the stress acting on the particle, are a maximum at the crack-plane then failure should be expected to initiate from this point. When $\mathrm{x}=0$, the Eq. (3) becomes:

$$
\tau=\frac{\mathrm{n}}{2} \mathrm{E}_{\mathrm{p}} \mathrm{e}_{\mathrm{p}}
$$

If the particle deforms in an elastic manner (according to Hooke's law) then,

$$
\tau=\frac{\mathrm{n}}{2} \sigma_{\mathrm{p}}
$$

where $\sigma_{\mathrm{p}}$ is the particle stress. If particle fracture occurs when the stress in the particle reaches its ultimate tensile strength, $\sigma_{\mathrm{p} \text {,uts }}$, then setting the boundary condition at

$$
\sigma_{\mathrm{p}}=\sigma_{\mathrm{p}, \text { uts }}
$$

and substituting into Eq.(5) gives a relationship between the strength of the particle and the interfacial shear stress such that if

$$
\sigma_{\mathrm{P}, \mathrm{uts}}<\frac{2 \tau}{\mathrm{n}}
$$




\section{International Journal of Science and Research (IJSR) \\ ISSN (Online): 2319-7064 \\ Index Copernicus Value (2013): 6.14 | Impact Factor (2013): 4.438}

Then the particle will fracture. Similarly if interfacial debonding/yielding is considered to occur when the interfacial shear stress reaches its shear strength

$$
\tau=\tau_{\max }
$$

Then by substituting Eq. (8) into Eq.(5) a boundary condition for particle/matrix interfacial fracture can be established whereby,

$$
\tau_{\max }<\frac{\mathrm{n} \sigma_{\mathrm{p}}}{2}
$$

This approach suggests that the outcome of a matrix crack impinging on an embedded particle depends on the balance between the particle strength and the shear strength of the interface.

Surface tractions, or stresses acting on an internal datum plane, are typically decomposed into three mutually orthogonal components. One component is normal to the surface and represents direct stress. The other two components are tangential to the surface and represent shear stresses. The definition of the tractions in terms of stresses is shown in figure 1.

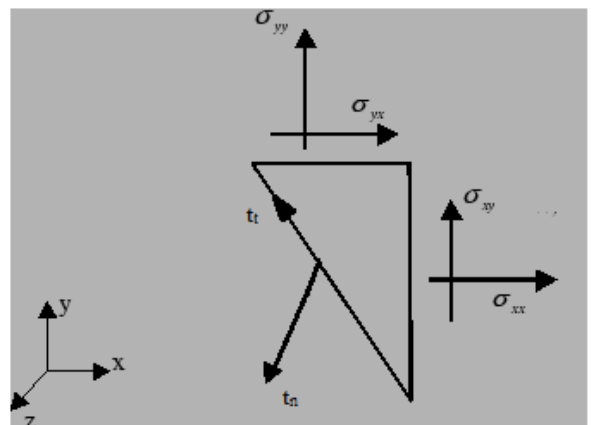

Figure 1: The 2-D free-body diagram with tractions and stress components

A linear stress-strain relation [14-18] at the macro level can be formulated as follows:

$$
\bar{\sigma}=\overline{\mathrm{C}} \bar{\varepsilon}
$$

where $\bar{\sigma}$ is macro stress, and $\bar{\varepsilon}$ represents macro total strain and $\overline{\mathrm{C}}$ and is macro stiffness matrix. For plane strain conditions, the macro stress- macro strain relation [3-12] is as follows:

$$
\left\{\begin{array}{l}
\overline{\sigma_{\mathrm{x}}} \\
\overline{\bar{\sigma}_{\mathrm{y}}}
\end{array}\right\}=\left[\begin{array}{ccc}
\overline{\mathrm{C}_{11}} & \overline{\mathrm{C}_{12}} & 0 \\
\overline{\mathrm{C}_{21}} & \overline{\mathrm{C}_{22}} & 0 \\
0 & 0 & \overline{\mathrm{C}_{33}}
\end{array}\right] \times\left\{\begin{array}{c}
\overline{\overline{\varepsilon_{\mathrm{x}}}} \\
\overline{\bar{\varepsilon}_{\mathrm{y}}} \\
\overline{\gamma_{\mathrm{xy}}}
\end{array}\right\}
$$

The interfacial tractions can be obtained by transforming the micro stresses at the interface as given in Eq. (3):

$$
t=\left\{\begin{array}{l}
t_{z} \\
t_{n} \\
t_{t}
\end{array}\right\}=T \sigma
$$

$$
\text { where, } \mathrm{T}=\left[\begin{array}{ccc}
0 & 0 & 0 \\
\cos ^{2} \theta & \sin ^{2} \theta & 2 \sin \theta \cos \theta \\
-\sin \theta \cos \theta & \sin \theta \cos \theta & \cos ^{2} \theta-\sin ^{2} \theta
\end{array}\right]
$$

The matrix material was AA1100 alloy. The reinforcement nanoparticulate was $\mathrm{TiN}$ of average size $100 \mathrm{~nm}$. The properties of materials used in the present work are given in table 1. The volume fractions of TiN nanoparticles were $10 \%$ and $30 \%$. In this paper, a square RVE (figure 2) was prepared to understand the thermoelastic behavior AA1100/ TiN nanocomposites. The PLANE183 element was used in the matrix and the nanoparticle in the RVE models. The interphase be- tween nanoparticle and matrix was discretized with CONTACT172 element [20]. Both isothermal and hydrostatic pressure loads were applied at the same time on the RVE models.

Table 1: Mechanical properties of AA1100 matrix and TiN nanoparticles

\begin{tabular}{|l|l|l|}
\hline Property & AA1100 & TiN \\
\hline Density, g/cc & 2.71 & 5.22 \\
\hline Elastic modulus, GPa & 68.9 & 251 \\
\hline Ultimate tensile strength, MPa & 110 & - \\
\hline Poisson's ratio & 0.33 & 0.25 \\
\hline CTE, $\mu \mathrm{m} / \mathrm{m}^{\circ}{ }^{\circ} \mathrm{C}$ & 21.8 & 9.35 \\
\hline Thermal Conductivity, W/m-K & 220.0 & 110 \\
\hline Specific heat, J/kg-K & 904 & 1960 \\
\hline Density, g/cc & 2.71 & 5.22 \\
\hline Elastic modulus, GPa & 68.9 & 251 \\
\hline
\end{tabular}

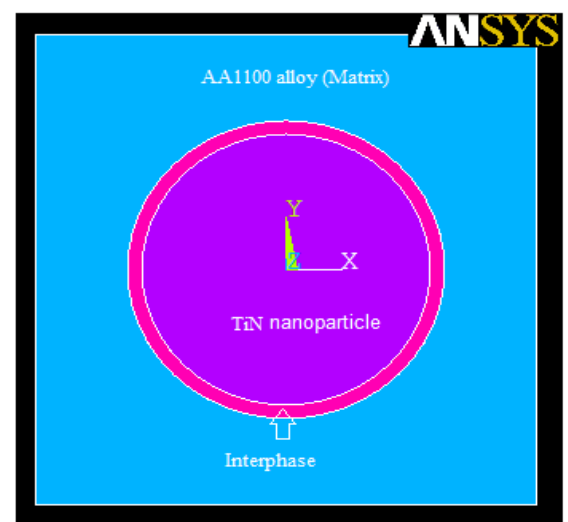

Figure 2: The RVE model

\section{Results and Discussion}

The finite element analysis (FEA) was carried out at $0^{\circ} \mathrm{C}$ to $300^{\circ} \mathrm{C}$ at constant hydrostatic pressure load applied on RVE models.

\subsection{Micromechanics of thermoelastic behavior}

The increase of temperature increased the strains along $\mathrm{x}$ and $y$ - directions of applied load (figure 3). The strains along the load direction $(\mathrm{x})$ were higher than those along the transverse direction (y) of the applied load. This was because of additive effect of elastic (tensile) and thermal strains along load direction; subtraction of elastic strains (compressive) from thermal strains along transverse direction [21].

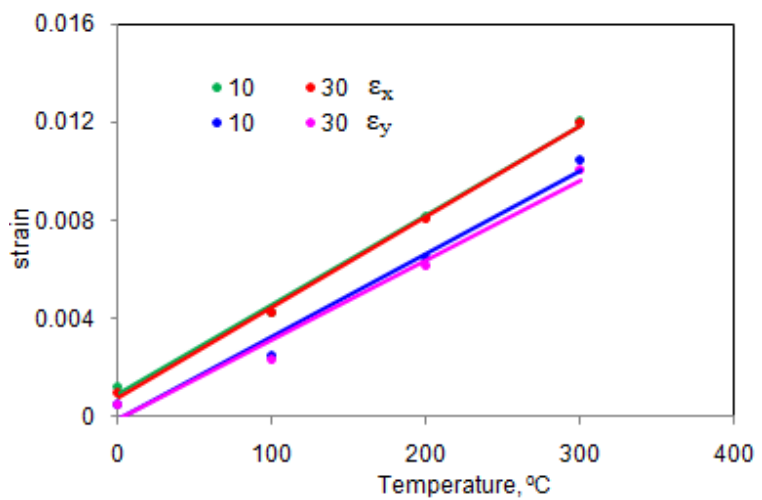

Figure 3: Influence of temperature on thermoelastic strain. 


\section{International Journal of Science and Research (IJSR) \\ ISSN (Online): 2319-7064}

Index Copernicus Value (2013): 6.14 | Impact Factor (2013): 4.438
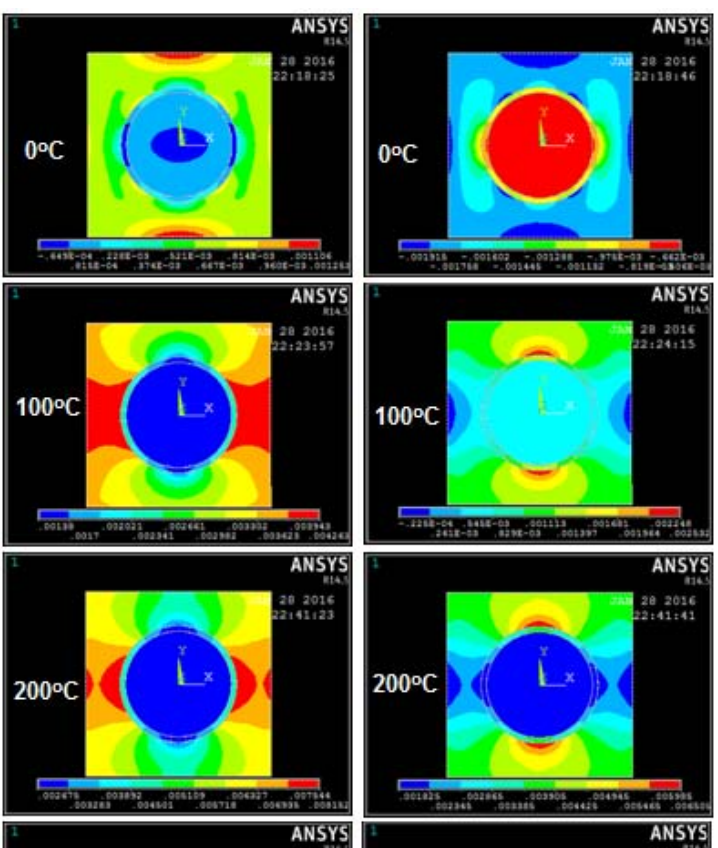

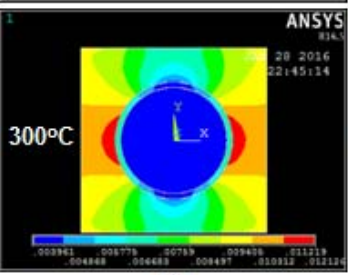

(a)

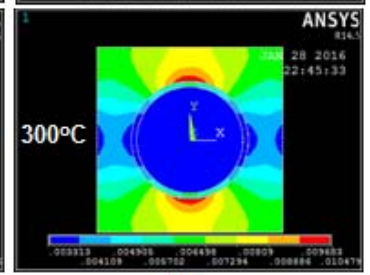

(b)
Figure 4: Raster images of strains induced in AA1100/10\% TiN composites: (a) $\varepsilon_{\mathrm{x}}$ and (b) $\varepsilon_{\mathrm{y}}$.
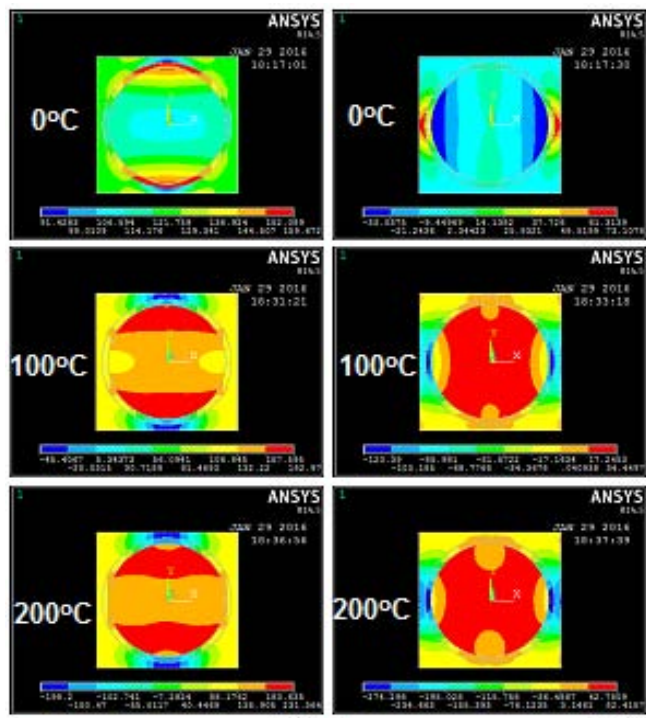

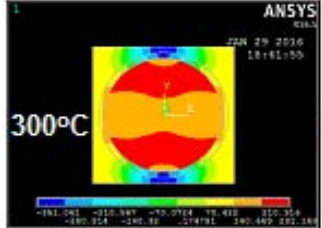

(a)

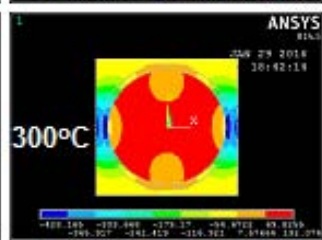

(b)
Figure 5: Raster images of strains induced in AA1100/30\% TiN composites: (a) $\varepsilon_{\mathrm{x}}$ and (b) $\varepsilon_{\mathrm{y}}$.

For composites having low volume fraction (10\%) of TIN nanoparticles, the matrix AA1100 alloy had exposed to large strains along $\mathrm{x}$-direction as the temperature changed from $0^{\circ} \mathrm{C}$ to $300^{\circ} \mathrm{C}$ temperature as showed in figure $4 \mathrm{a}$. The same kind of trend was observed along y-direction except at $0^{\circ} \mathrm{C}$ (figure $4 \mathrm{~b}$ ) wherein the nanoparticle (TiN) experienced high strains. For composites comprising high volume fraction $(30 \%)$ of TiN nanoparticles, large strains were induced either in nanoparticles or at the interphase as the temperature increased from $100^{\circ} \mathrm{C}$ to $300^{\circ} \mathrm{C}$ (figure 5).

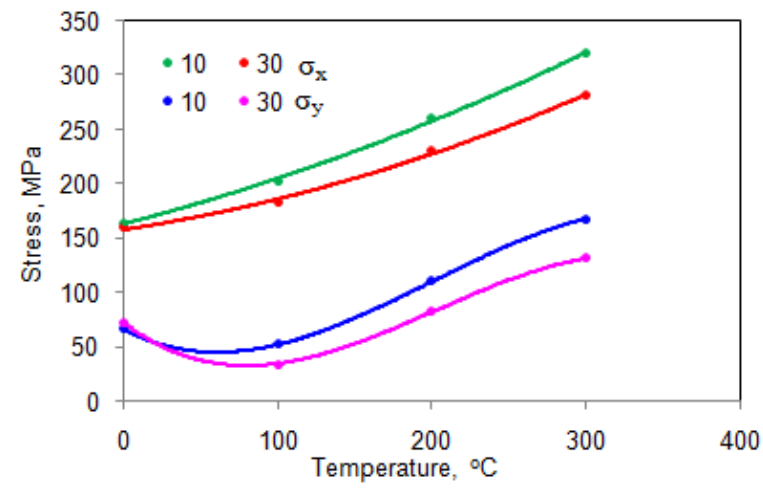

Figure 6: Influence of temperature on strength.

The stresses induced in the composites increased with the increase of temperature as shown in figure 6 . This indicates the softening of composites due to increase of temperature even though the hydrostatic pressure unchanged. The stress induced along $\mathrm{x}$-direction was higher than that induced along $\mathrm{y}$-direction of hydrostatic pressure loading.
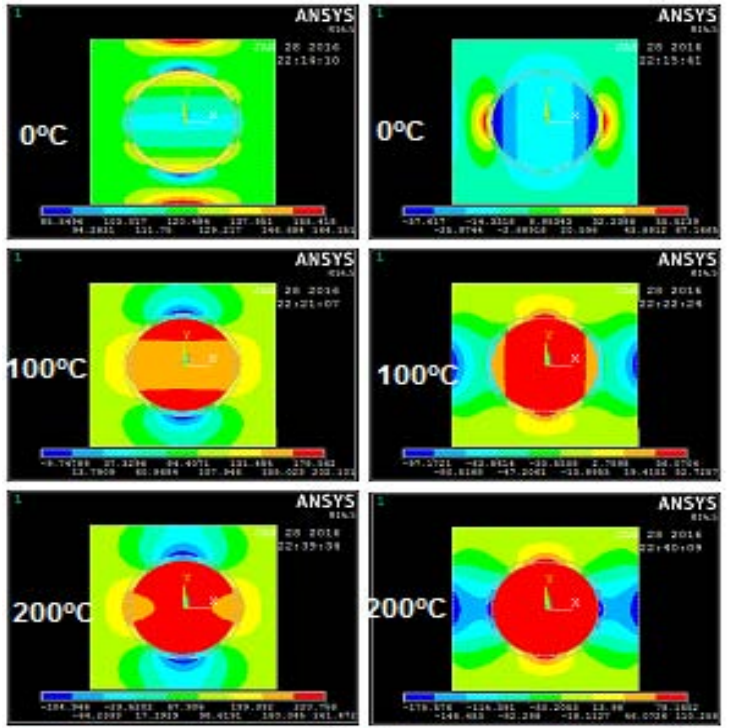

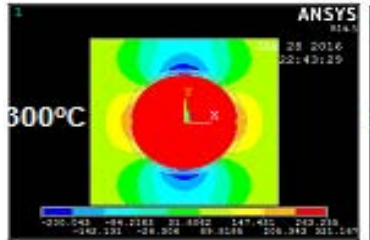

(a)

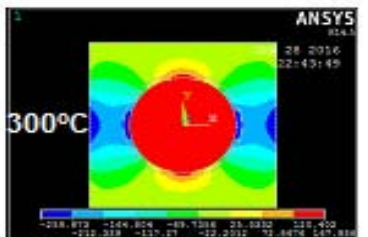

(b)
Figure 7: Raster images of stresses induced in AA1100/10\% TiN composites

Figures 7 and 8 show raster images of stresses induced in the composites having $10 \%$ and $30 \%$ TiN nanoparticles. The stress was very high either in TiN nanoparticles or at the interphase. The AA1100 matrix experienced the low stress due to its high ductility. This indicates that the load was transferred matrix to nanoparticle as the temperature increased from $0^{\circ} \mathrm{C}$ to $300^{\circ} \mathrm{C}$. Different color bands across the 


\section{International Journal of Science and Research (IJSR) \\ ISSN (Online): 2319-7064 \\ Index Copernicus Value (2013): 6.14 | Impact Factor (2013): 4.438}

nanoparticles indicate the occurrence of local stress variation within them.
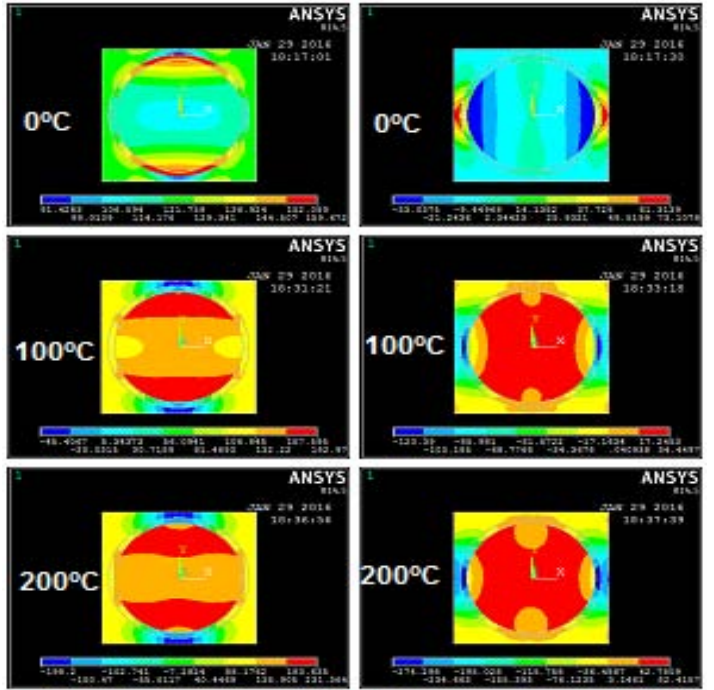

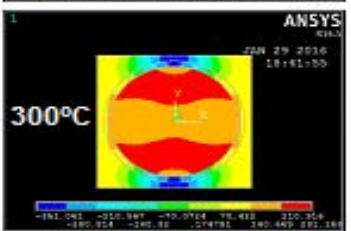

(a)

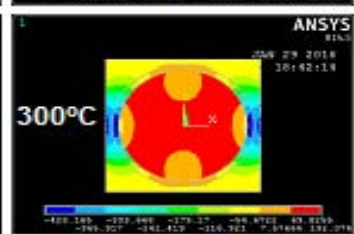

(b)
Figure 8: Raster images of stresses induced in AA1100/30\% TiN composites

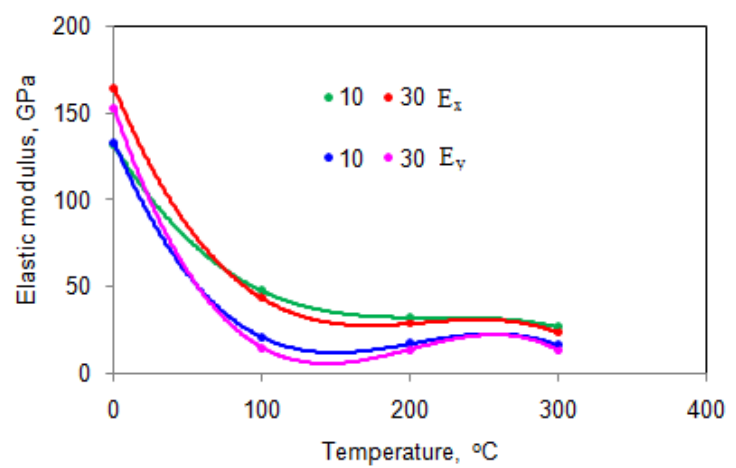

Figure 9: Influence of temperature on elastic modulus: (a) $\mathrm{E}_{\mathrm{x}}$ and (b) $\mathrm{E}_{\mathrm{y}}$.

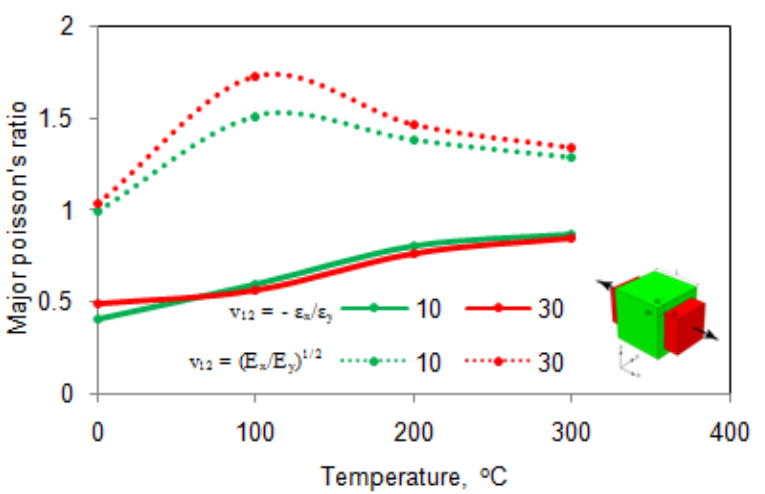

Figure 10: Influence of temperature on major Poisson's ratio.

The tensile elastic modulus decreased with the increase of temperature (figure 9). The elastic modulus was higher along $\mathrm{x}$-direction (load direction) than that along transverse (y) direction of hydrostatic loading. Even though strains developed along y-direction were low, the elastic modulus along $y$-direction was low owing to very low stress (numerator component of elastic modulus formula i.e. stress/strain) developed. The major Poisson's ratio increased with increase of temperature (figure 10). Poisson's ratio is bounded by the ratio of Young's moduli $\mathrm{E}$ as mentioned in figure 10.

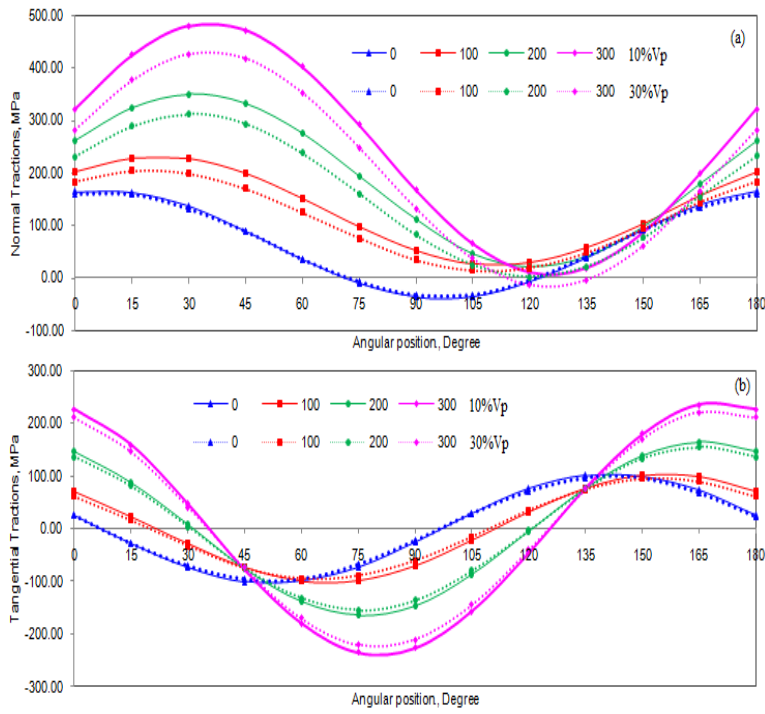

Figure 11: Interfacial tractions due to tensile loading: (a) normal and (b) tangential.

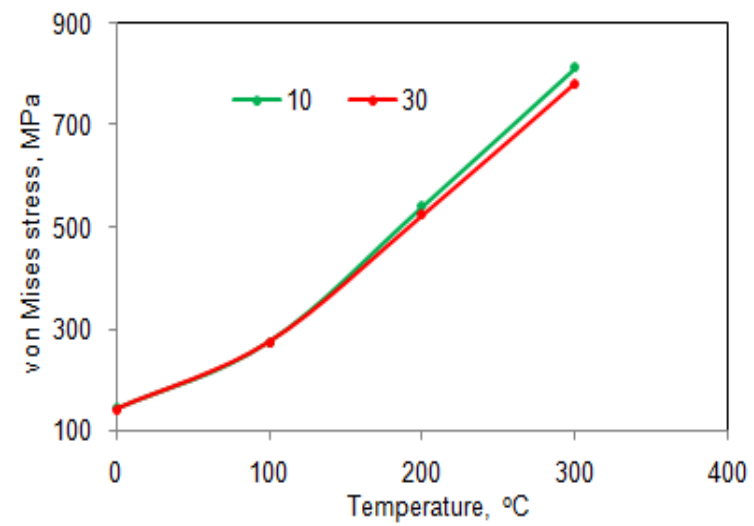

Figure 12: Influence of temperature on von Mises stress.

\subsection{Interfacial debonding and particulate fracture}

Figure 11 depicts the interfacial normal and tangential tractions developed in the composites. The normal and tangential tractions were increased with the increase of temperature, but they decreased with the increase of volume fraction of $\mathrm{TiN}$ in the composites. Figures 12 and 13 express the von Mises stress induced in the composites. The von Mises stress increased with the increase of temperature from $0^{\circ} \mathrm{C}$ to $300^{\circ} \mathrm{C}$ on account of increased softening. The interfacial debonding has occurred in the composites subjected to temperature in the range $0^{\circ}$ to $200^{\circ} \mathrm{C}$ (figure 12). The shear stress to cause the interface debonding was lower than the stress induced in the TIN nanoparticulates below $200^{\circ} \mathrm{C}$. But, the TiN particulate fracture was observed in the composites heated above $200^{\circ} \mathrm{C}$ (figure 14). The particulate strength was lower than that of the interface above $200^{\circ} \mathrm{C}$. This is owing to CTE (coefficient of thermal expansion) mismatch between TiN nanoparticulate and AA1100 alloy matrix. In all the compo- 


\section{International Journal of Science and Research (IJSR) \\ ISSN (Online): 2319-7064 \\ Index Copernicus Value (2013): 6.14 | Impact Factor (2013): 4.438}

sites, the interphase was fractured. TiN nanoparticles were subjected to high stresses as illustrated in figure 14. The scanning electron microscope (SEM) images (figure 15) demonstrate the same kind of phenomenon in the composites comprising of $30 \%$ of TiN. The interface/interphase fracture (A) around the TiN nanoparticles was clearly observed. At $300^{\circ} \mathrm{C}$, narrow tear bands (B) were revealed in the TiN nanoparticles.
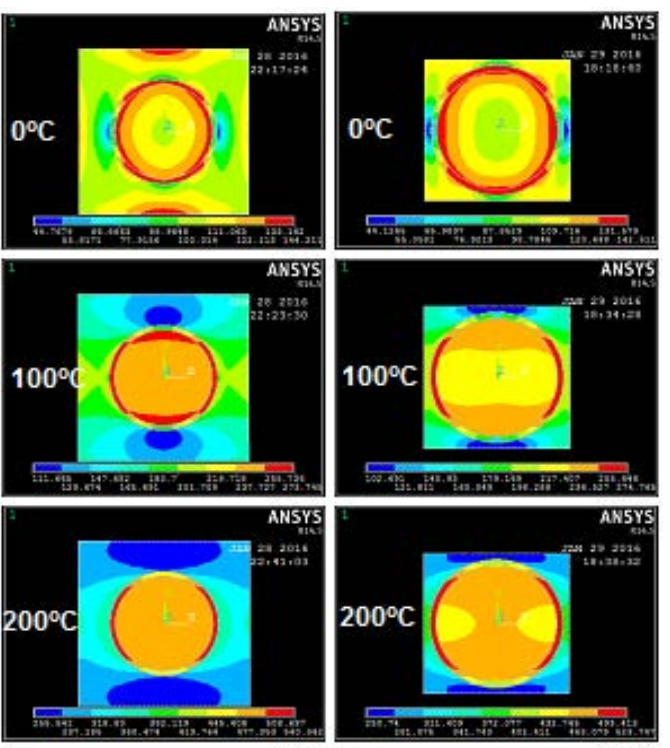

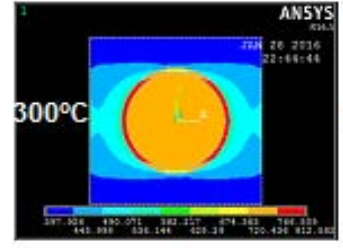

(a)

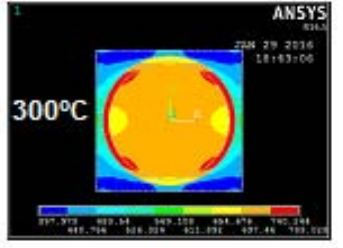

(b)
Figure 13: Raster images of von Mises stress of AA1100/TiN composites: (a) 10\% TiNand (b) 30\% TiN.
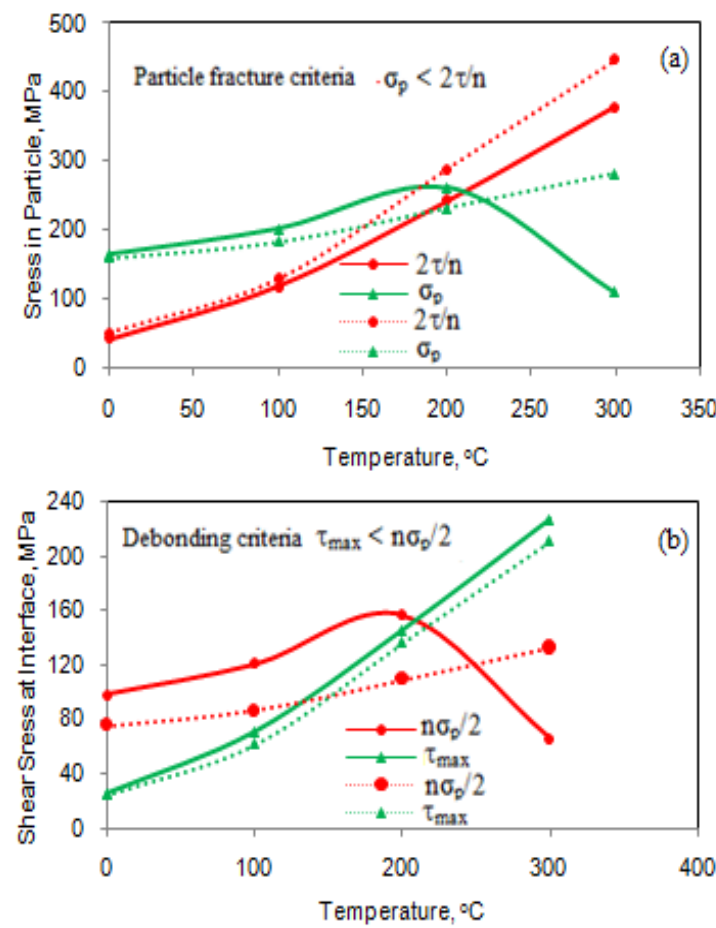

Figure 14: Fracture criteria of: (a) particulate and (b) interface.

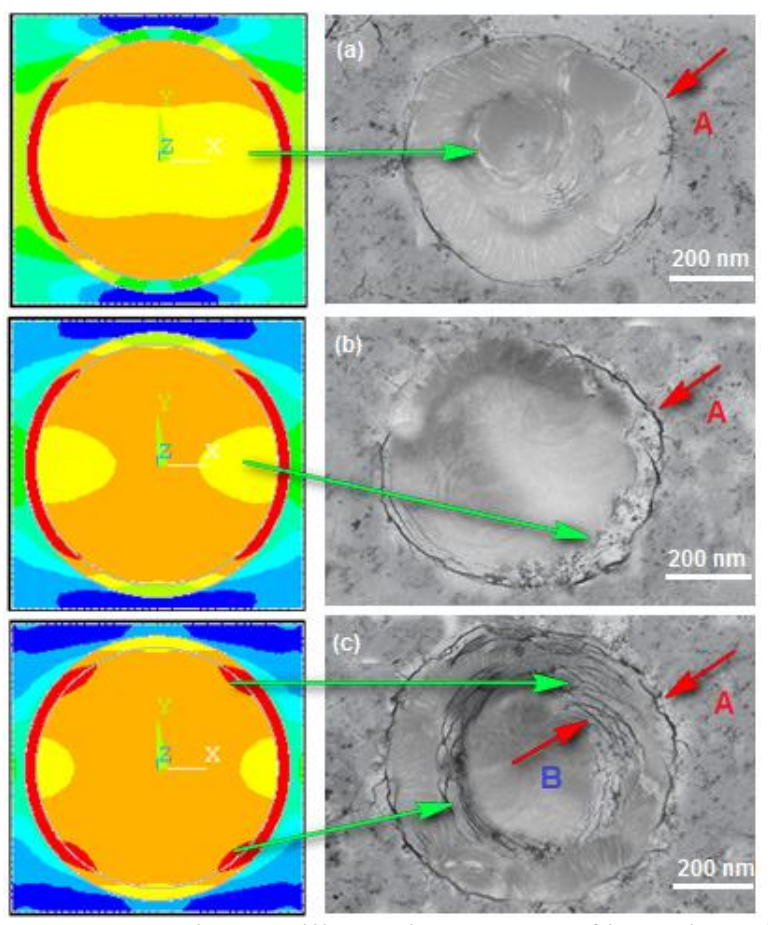

Figure 13: SEM images illustrating rupture of interphase (A) and stress or tear bands (B) in nanoparticles: (a) $100^{\circ} \mathrm{C}$, (b) $200^{\circ} \mathrm{C}$ and (c) $300^{\circ} \mathrm{C}$.

\section{Conclusions}

The thermoelastic strains and stresses induced in the AA1100/TiN composites were directly proportional to temperature. The elastic moduli decreased with increase of temperature. The debonding of interface/interphase between AA1100 alloy matrix and TiN nanoparticle was observed in the composites heated below $200^{\circ} \mathrm{C}$. TiN nanoparticles were fractured when the composites were heated above $200^{\circ} \mathrm{C}$.

\section{References}

[1] A. C. Reddy, B. Kotiveerchari and P. Rami Reddy, "Saving of Thermal Energy in Air-Gap Insulated Pistons Using Different Composite Materials for Crowns," International Journal of Scientific \& Engineering Research, 6 (3), pp. 71-74, 2015.

[2] Y. Brechet, J.D. Embury, S. Tao and L. Luo, "Damage initiation in metal matrix composites," Acta Metallurgica et Materialia, 39, pp. 1781-1786, 1991.

[3] A. C. Reddy and B. Kotiveerachari, "Influence of microstructural changes caused by ageing on wear behaviour of Al6061/SiC composites," Journal of Metallurgy \& Materials Science, 53(1), pp. 31-39, 2011.

[4] A. C. Reddy, "Tensile properties and fracture behavior of 6063/SiCP metal matrix composites fabricated by investment casting process," International Journal of Mechanical Engineering and Materials Sciences, 3(1), pp. 73-78, 2010.

[5] A. C. Reddy, "Experimental Evaluation of Elastic Lattice Strains in the Discontinuously SiC Reinforced Alalloy Composites," National Conference on Emerging Trends in Mechanical Engineering, Nagapur, 05-06th February 2004.

[6] T. Christman, K. Heady and T. Vreeland, "Consolidation of $\mathrm{Ti}-\mathrm{SiC}$ particle-reinforced metal-matrix compo- 


\section{International Journal of Science and Research (IJSR) \\ ISSN (Online): 2319-7064}

Index Copernicus Value (2013): 6.14 | Impact Factor (2013): 4.438

sites," Scripta Metallurgica et Materialia, 25, pp. 631636, 1991.

[7] A. C. Reddy and Essa Zitoun, "Tensile properties and fracture behavior of $6061 / \mathrm{Al}_{2} \mathrm{O}_{3}$ metal matrix composites fabricated by low pressure die casting process," International Journal of Materials Sciences, 6(2), pp. 147$157,2011$.

[8] A. C. Reddy and Essa Zitoun, "Matrix al-alloys for alumina particle reinforced metal matrix composites, Indian Foundry Journal," 55(1), pp. 12-16, 2009.

[9] T.S. Srivatsan, "Microstructure, tensile properties and fracture behavior of $\mathrm{Al}_{2} \mathrm{O}_{3}$ particulate-reinforced aluminum alloy metal matrix composites," Journal of Materials Science, 31(5), pp.1375-1388, 1996.

[10]A. C. Reddy, "Studies on fracture behavior of brittle matrix and alumina trihydrate particulate composites," Indian Journal of Engineering \& Materials Sciences, 9(5), pp.365-368, 2002.

[11]A. C. Reddy, "Analysis of the Relationship Between the Interface Structure and the Strength of CarbonAluminum Composites," NATCON-ME, Bangalore, 1314th March 2004.

[12] C. F. Deng, D. Z. Wang, X. X. Zhang, Y. X. Ma, "Damping characteristics of carbon nanotube reinforced aluminum composite," Material Letters, 61, pp. 32293231, 2007.

[13] A. C. Reddy, "Evaluation of Debonding and Dislocation Occurrences in Rhombus Silicon Nitride Particulate/AA4015 Alloy Metal Matrix Composites," National Conference on Materials and Manufacturing Processes, Hyderabad, 27-28 February 1998.

[14] A. C. Reddy, "Assessment of Debonding and Particulate Fracture Occurrences in Circular Silicon Nitride Particulate/AA5050 Alloy Metal Matrix Composites," National Conference on Materials and Manufacturing Processes, Hyderabad, 27-28 February 1998.

[15] A. C. Reddy, "Evaluation of Debonding and Dislocation Occurrences in Rhombus Silicon Nitride Particulate/AA4015 Alloy Metal Matrix Composites," 1st National Conference on Modern Materials and Manufacturing, 19-20 December 1997.

[16] A. C. Reddy, "Effect of Particle Loading on Microealstic Behavior and interfacial Tractions of Boron Carbide/AA4015 Alloy Metal Matrix Composites," 1st International Conference on Composite Materials and Characterization, Bangalore, 14-15 March 1997.

[17] A. C. Reddy, "Interfacial Debonding Analysis in Terms of Interfacial Tractions for Titanium Boride/AA3003 Alloy Metal Matrix Composites," 1st National Conference on Modern Materials and Manufacturing, 19-20 December 1997, Pune.

[18]A. C. Reddy, "Reckoning of Micro-stresses and interfacial Tractions in Titanium Boride/AA2024 Alloy Metal Matrix Composites," 1st International Conference on Composite Materials and Characterization, Bangalore, 14-15 march 1997.

[19] S. Suresh, A. Mortensen, A. Needleman, "Fundamentals of MMCs," Butterworth-Heinemann Publishing Company, Stoneham, USA, 1993.

[20] C.R. Alavala, "Finite Element methods: Basic Concepts and Applications," PHI Learning Pvt. Ltd., New Delhi, 2008.
[21] A. C. Reddy, "Influence of strain rate and temperature on superplastic behavior of sinter forged Al6061/SiC metal matrix composites," International Journal of Engineering Research \& Technology, 4(2), pp.189-198, 2011. 